\title{
Development of a self-replicating plasmid system for Mycoplasma hyopneumoniae
}

\author{
Gareth A Maglennon ${ }^{1}$, Beth S Cook ${ }^{1}$, Dominic Matthews ${ }^{1}$, Alannah S Deeney ${ }^{1}$, Janine T Bossé ${ }^{2}$, Paul R Langford ${ }^{2}$, \\ Duncan J Maskell ${ }^{3}$, Alexander W Tucker ${ }^{3}$, Brendan W Wren ${ }^{4}$, Andrew N Rycroft ${ }^{1 *}$ and BRaDP1T consortium
}

\begin{abstract}
Mycoplasma hyopneumoniae is a prevalent swine respiratory pathogen that is a major cause of economic loss to pig producers. Control is achieved by a combination of antimicrobials, vaccination and management practices, but current vaccines offer only partial control and there is a need for improved preventative strategies. A major barrier to advances in understanding the pathogenesis of $M$. hyopneumoniae and in developing new vaccines is the lack of tools to genetically manipulate the organism. We describe the development and optimisation of the first successful plasmid-based system for the genetic manipulation of $M$. hyopneumoniae. Our artificial plasmids contain the origin of replication (oriC) of $M$. hyopneumoniae along with tetM, conferring resistance to tetracycline. With these plasmids, we have successfully transformed M. hyopneumoniae strain 232 by electroporation, generating tetracycline resistant organisms. The persistence of extrachromosomal plasmid and maintenance of plasmid DNA over serial passages shows that these artificial plasmids are capable of self-replication in M. hyopneumoniae. In addition to demonstrating the amenability of $M$. hyopneumoniae to genetic manipulation and in optimising the conditions necessary for successful transformation, we have used this system to determine the minimum functional oriC of $\mathrm{M}$. hyopneumoniae. In doing so, we have developed a plasmid with a small oriC that is stably maintained over multiple passages that may be useful in generating targeted gene disruptions. In conclusion, we have generated a set of plasmids that will be valuable in studies of $M$. hyopneumoniae pathogenesis and provide a major step forward in the study of this important swine pathogen.
\end{abstract}

\section{Introduction}

Bacteria in the genus Mycoplasma are characterised by their lack of a cell wall, small genome size and utility in synthetic biology. They are responsible for a number of important diseases in humans and other animals. Among the most important species is Mycoplasma hyopneumoniae that is the cause of enzootic pneumonia, a chronic swine respiratory disease of global economic importance to pig producers [1]. Partial control of M. hyopneumoniae is achieved by a combination of management practices, antimicrobials and immunisation with commercially available vaccines [1]. Although current vaccines improve performance parameters and reduce the severity of lung lesions, there is a need for more effective vaccines, particularly in response to concerns regarding the current over-use of antimicrobials in production animals. Progress in

\footnotetext{
* Correspondence: arycroft@rvc.ac.uk

'Department of Pathology and Pathogen Biology, The Royal Veterinary College, Hawkshead Lane, North Mymms, Hatfield AL9 7TA, United Kingdom Full list of author information is available at the end of the article
}

understanding the molecular basis of M. hyopneumoniae pathogenesis is essential for improved intervention measures such as vaccine development, but this has been severely hampered by the lack of tools to genetically manipulate the organism [2]. Such tools may prove valuable in identifying and studying determinants of virulence in the mycoplasma genome that are central to the ability of the organism to cause disease. Some advances have been made with other mycoplasmas using transposon mutagenesis to generate random insertional mutants that can be screened for the expression of virulence factors using in vivo or in vitro model systems [3-9]. Such techniques have not been reported to date for M. hyopneumoniae. Additionally, transposon mutagenesis techniques produce random insertions into the mycoplasma genome, thus it can be difficult to isolate mutants with disruptions in particular genes of interest. A few mycoplasmas have also been transformed with artificial plasmids that are capable of self-replication

\section{Biomed Central}

(c) 2013 Maglennon et al.; licensee BioMed Central Ltd. This is an Open Access article distributed under the terms of the Creative Commons Attribution License (http://creativecommons.org/licenses/by/2.0), which permits unrestricted use, distribution, and reproduction in any medium, provided the original work is properly cited. 
[10-14]. These plasmids contain the origin of replication (oriC) of the mycoplasma along with an antimicrobial resistance gene cassette to facilitate genetic selection. Following transformation, these plasmids are initially replicated extrachromosomally, but can undergo integration into the host cell chromosome by recombination, owing to homology between the plasmid oriC and the oriC of the mycoplasma chromosome. In addition to demonstrating the amenability of mycoplasmas to genetic manipulation, in some cases oriC-based plasmids have been useful in promoting the generation of mutations in target genes by homologous recombination $[11,12]$. Plasmid stability can be increased by reducing the size of the plasmid oriC to the minimum that is functional, therefore reducing the likelihood of incorporation of the plasmid by homologous recombination into the host chromosome $[11,12]$. DNA sequences homologous to genes of interest in the mycoplasma genome could then be incorporated into the plasmid, and used to promote homologous recombination at specific sites in the mycoplasma chromosome.

In this study, a simple oriC-based plasmid system was developed as a method of determining the susceptibility of $M$. hyopneumoniae to transformation and optimising the conditions necessary for transformation. Requiring only the $M$. hyopneumoniae origin of replication and a suitable antimicrobial selection marker, we anticipated that such simple plasmids would be more likely to achieve successful transformation than, for example, a transposon mutagenesis system that also requires successful transposition into the host cell chromosome. The ability to transform M. hyopneumoniae has been long anticipated. Here we describe the generation of an oriC-based system for $M$. hyopneumoniae that facilitates the genetic transformation of this important pathogen.

\section{Materials and methods}

Bacterial strains and culture

Mycoplasma hyopneumoniae strain 232 [2] was grown in Friis medium as described by Kobisch and Friis [15]. Liquid cultures were grown at $37^{\circ} \mathrm{C}$ in a static incubator in airtight culture tubes. For growth on solid medium, a final concentration of $0.8 \%$ w/v purified agar was added to Friis medium and plates were incubated at $37{ }^{\circ} \mathrm{C}$ with $5 \% \mathrm{CO}_{2}$. Colonies were visualised by light microscopy at $\times 35$ magnification using a stereoscopic microscope. For the selection of transformed $M$. hyopneumoniae, tetracycline hydrochloride (Sigma-Aldrich Ltd, Gillingham, UK) or puromycin dihydrochloride (Sigma-Aldrich Ltd, Gillingham, UK) were added to a final concentration of $0.2-2.0 \mu \mathrm{g} / \mathrm{mL}$ and $5 \mu \mathrm{g} / \mathrm{mL}$ respectively. For molecular cloning, Escherichia coli strain DH5 $\alpha$ (Invitrogen Ltd, Paisley, UK) was grown in Luria-Bertani medium containing $50 \mu \mathrm{g} / \mathrm{mL}$ ampicillin at $37{ }^{\circ} \mathrm{C}$ with shaking at $220 \mathrm{rpm}$. For the selection of organisms expressing the tetracycline resistance gene, tet $M$,
$5 \mu \mathrm{g} / \mathrm{mL}$ tetracycline hydrochloride was also added to solid medium.

\section{Transformation of $M$. hyopneumoniae}

Mycoplasma hyopneumoniae strain 232 was grown in liquid culture until mid/late logarithmic phase $\left(\sim 10^{8} \mathrm{CFU} / \mathrm{mL}\right)$, as determined by an acid colour change in the phenol red $\mathrm{pH}$ indicator. Cells were collected by centrifugation at $9000 \times g$ at $4{ }^{\circ} \mathrm{C}$ for $10 \mathrm{~min}$ and were washed three times in an equivalent volume of electroporation buffer (272 mM sucrose, $8 \mathrm{mM}$ HEPES, $\mathrm{pH}$ 7.4). After the final wash cells were re-suspended in electroporation buffer such that $100 \mu \mathrm{L}$ cells was equivalent to approximately $2 \mathrm{~mL}$ of mycoplasma culture. Mycoplasmas were incubated on ice with plasmid DNA for $30 \mathrm{~min}$ and then transferred to a pre-chilled $0.2 \mathrm{~cm}$ electroporation cuvette (Bio-Rad Ltd, Hemel Hempstead, UK). Electroporation was performed using a Gene Pulser system (Bio-Rad Ltd, Hemel Hempstead, UK). Standard electroporation conditions were $2.5 \mathrm{kV}, 100 \Omega$ and $25 \mu \mathrm{F}$. Immediately after electroporation, $900 \mu \mathrm{L}$ chilled Friis medium were added. After incubation for a further 15 min on ice, cells were transferred to a microcentrifuge tube and incubated for a further $3 \mathrm{~h}$ at $37{ }^{\circ} \mathrm{C}$. Cultures were then plated onto solid Friis medium containing $0.2-$ $2.0 \mu \mathrm{g} / \mathrm{mL}$ tetracycline and were incubated at $37{ }^{\circ} \mathrm{C}$ in $5 \%$ $\mathrm{CO}_{2}$ for $10-14$ days.

\section{Plasmid construction}

Sequences of oligonucleotide primers used in the construction of plasmids are shown in Table 1. Polymerase chain reaction (PCR) was performed using a Phusion High-Fidelity DNA Polymerase kit (NEB Ltd, Hitchin, UK) according to the manufacturers instructions. PCR-amplified DNA products were cloned into plasmids at restriction sites added to oligonucleotides as shown in Table 1 and in plasmids as shown in Figures 1 and 2. The oriC of M. hyopneumoniae strain 232 was predicted based on nucleotide sequence similarity with other Mycoplasma spp. for which a functional oriC has been verified [11,12,14]. Typically, the oriC encompasses short AT-rich regions flanking $d n a A$ and containing DnaA boxes. A search of the M. hyopneumoniae strain 232 genome [GenBank: AE017332] revealed two DnaA boxes (each with two bp mismatches with the Escherichia coli consensus sequence 5'-TTATCCACA-3') upstream and downstream of the dnaA gene within AT-rich regions (Figure 1A). Plasmid pMHO (Figure 1D) was generated by cloning a PCRamplified $2.1 \mathrm{kbp}$ sequence encompassing dnaA and the AT-rich regions flanking each end of the gene into the pGEM-T cloning vector (Promega Ltd, Southampton, $\mathrm{UK})$. The tetM gene and promoter from Enterococcus faecalis were amplified from plasmid pIVT-1 [5] and cloned into $\mathrm{pMHO}$ to produce $\mathrm{pMHO}-1$. To generate pMHO-2, the tet $M$ gene from the plasmid pSRT2 [11] 
Table 1 Oligonucleotide sequences.

\begin{tabular}{|c|c|c|c|}
\hline PCR product & Size (bp) & Restriction site & Oligonucleotide sequence ( $\left.5^{\prime}-3^{\prime}\right)$ \\
\hline \multirow[t]{2}{*}{ M. hyopneumoniae strain 232 oric- i } & 2130 & Ncol & F - AGGCCATGGTTGTTAATTATTGCTTGAAATTC \\
\hline & & Spel & $R$ - AGTACTAGTAAACTITATAGGAAAGTTCG \\
\hline \multirow[t]{2}{*}{ M. hyopneumoniae strain 232 oric- ii } & 1823 & Ncol & F - GATGCCATGGTTGGTTGATAAGTTCGCTTC \\
\hline & & Spel & R - GTAGACTAGTCATTCTITCAATTTGTCATTC \\
\hline \multirow[t]{2}{*}{ M. hyopneumoniae strain 232 oric- iii } & 859 & Ncol & F - GATGCCATGGTTGGTTGATAAGTTCGCTTC \\
\hline & & Spel & $R$ - GCTCACTAGTGACAATCAGTTTAAAAATTCAC \\
\hline \multirow[t]{2}{*}{ M. hyopneumoniae strain 232 oric- iii } & 859 & Aatll & F - GCAGGACGTCTTGGTTGATAAGTTCGCTCC \\
\hline & & Ncol & $R$ - GACGCCATGGGACAATCAGTTTAAAAATTCAC \\
\hline \multirow[t]{2}{*}{ M. hyopneumoniae strain 232 oric- iv } & 422 & Ncol & F - GCATCCATGGATATTGTGCATGCCCGCGGATAT \\
\hline & & Spel & R - GTAGACTAGTCATTCTITCAATTTGTCATTC \\
\hline \multirow[t]{2}{*}{ M. hyopneumoniae strain 232 oric- $v$} & 280 & Aatll & F - GCAGGACGTCTTGGTTGATAAGTTCGCTCC \\
\hline & & Ncol & R - CGTACCATGGCCTAATTTGCTGTGTTCTAA \\
\hline \multirow[t]{2}{*}{ tetM + spiralin promoter from plasmid pSRT2 } & 2320 & Pstl & F - TAACTGCAGCAAAAGCTTGCATGCCTGCA \\
\hline & & Spel & $R$ - GTCACTAGTCAGTTCAGATCTTTATATAAC \\
\hline \multirow[t]{2}{*}{ tetM from plasmid pIVT } & 2109 & Spel & F - ATCTACTAGTCATGTGATTCTAAAGTATCC \\
\hline & & Pstl & $R$ - GATCTGCAGCTTATTTAACAAGAAACC \\
\hline \multirow[t]{2}{*}{ tetM (without promoter) from plasmid pSRT2 } & 1963 & BamHI/Pstl & F - GAACTGCAGGATCCATGGAGGAAAATCACATGA \\
\hline & & Sall & $R$ - CCCGGTCGACTTATATAACAACTTAAATTAC \\
\hline \multirow[t]{2}{*}{ M. hyopneumoniae strain 232 P97 promoter } & 619 & $\mathrm{BamHI}$ & F - GAATGGATCCCCAACAATTCCGGCAGTC \\
\hline & & Spel & $R$ - GCTAACTAGTACGGGGATTTAAAACAGAAAC \\
\hline \multirow[t]{2}{*}{ M. hyopneumoniae strain 232 ldh promoter } & 421 & Spel & F - GGCTAACTAGTATAGAATITTGCAATTAAAG \\
\hline & & $\mathrm{BamHI}$ & R - CTTAGGATCCATTTATACTCGTATTTGTTAT \\
\hline \multirow[t]{2}{*}{ M. hyorhinis oriC } & 1479 & Ncol & F - GACTCCATGGTCGGAATCGAGATTCCTAATT \\
\hline & & Spel & R - GCCTACTAGTCTACACCTTCGATTTCTCTAA \\
\hline \multirow[t]{2}{*}{ M. pulmonis oriC } & 1909 & Ncol & F - ATTAGCCATGGCACTCTGGTCAGCGCTAGATC \\
\hline & & Nhel & R - TCGCGCTAGCCTAACTTGAAAATAAGCTCC \\
\hline \multirow[t]{2}{*}{ M. conjunctivae oriC } & 2307 & Ncol & F - GATACCATGGTATGCCTITGGTCTAGGATG \\
\hline & & Xbal & R - CGATGTCTAGACCCTTGAACAAATATACCA \\
\hline \multirow[t]{2}{*}{ M. ovipneumoniae oriC } & 2102 & Ncol & F - AGTCCATGGTCAATTATTGCTTGGAATTC \\
\hline & & Spel & R - CGTACTAGTAAACTITATAAGAAAGTTCGCT \\
\hline \multirow[t]{2}{*}{ bla gene (DIG-labelled probe) } & 860 & N/A & F - CCAATGCTTAATCAGTGAGG \\
\hline & & & R - GTATGAGTATTCAACATTTCCG \\
\hline \multirow[t]{2}{*}{ tetM (DIG-labelled probe) } & 406 & N/A & $F-$ GTGGACAAAGGTACAACGAG \\
\hline & & & R - CGGTAAAGTTCGTCACACAC \\
\hline
\end{tabular}

Oligonucleotide sequences are shown along with the size of the PCR product generated and the template DNA used. Restriction enzyme sites (where applicable) that were added to the $5^{\prime}$ end of the oligonucleotide are shown in italics. Forward (F) and reverse (R) oligonucleotides are shown.

was amplified by PCR and cloned into pMHO. The tetM gene of pMHO-2 contains the promoter sequence of the spiralin gene of Spiroplasma citri. To generate plasmids pMHO- 3 and pMHO-4, the tetM gene minus the spiralin gene promoter sequence was amplified from pSRT2 and cloned into pMHO. The predicted promoter regions of the P97 ciliary adhesin gene (619 bp) and the lactate dehydrogenase (ldh) gene (421 bp) were amplified by PCR from M. hyopneumoniae strain 232 and placed upstream of the tetM gene start codon to produce plasmids pMHO-3 and pMHO-4 respectively. The oriC regions of M. hyorhinis [GenBank: CP002170.1] [16], M. pulmonis [GenBank: NC_002771.1] [17], M. conjunctivae [GenBank: NC_012806.1] [18] and M. ovipneumoniae [GenBank: AFHO00000000.1] [19] were determined using the same criteria as for $M$. hyopneumoniae (location 

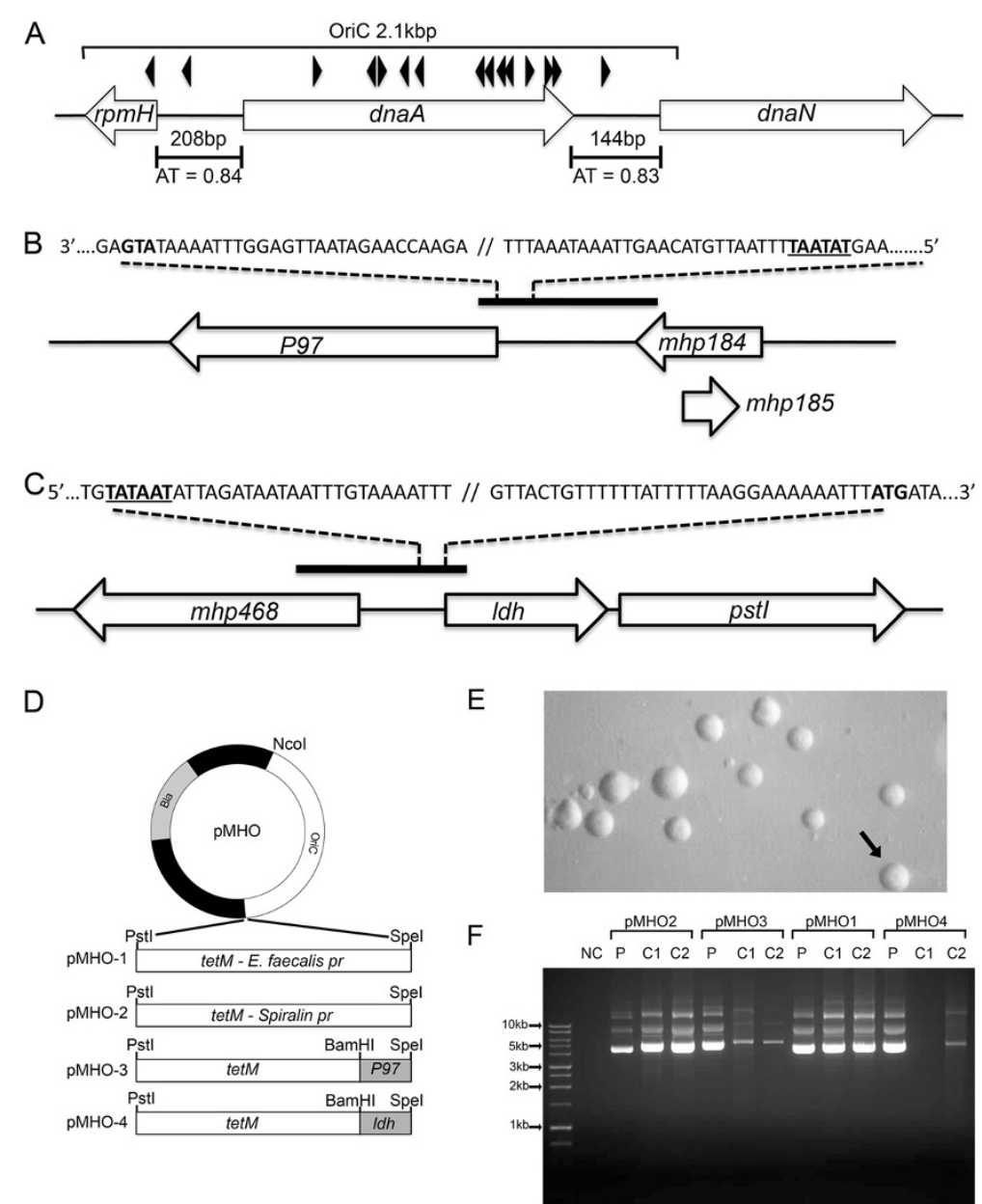

Figure 1 oriC plasmid construction. A $2.1 \mathrm{kbp}$ oriC region of M. hyopneumoniae strain 232 was predicted based on the location of putative DnaA boxes (black arrowheads), the location of dnaA and the presence of short AT-rich regions of $144 \mathrm{bp}$ and $208 \mathrm{bp}$ with an AT content of 0.83 and 0.84 respectively $(\mathbf{A})$. The $P 97$ gene $(\mathbf{B})$ and $/ d h$ gene $(\mathbf{C})$ promoter sequences were predicted based on proximity to the ATG start codon (shown in bold) and putative TATA box location (underlined). The oriC sequence was cloned into the Ncol and Spel restriction sites of pGEM-T to generate plasmid $\mathrm{pMHO}$. The tetM gene with the E. faecalis, spiralin gene, P97 and Idh promoter sequence was cloned into the Pstl and Spel sites to produce plasmids $\mathrm{pMHO}-1$, pMHO-2, pMHO-3 and pMHO-4 respectively (D). M. hyopneumoniae strain 232 was transformed with each plasmid and transformants ( $\mathrm{PMHO}-2$ in E) grown in Friis medium with tetracycline selection. After 3 passages, plasmid DNA was extracted from two individual clones (C1 and C2) and analysed by agarose gel electrophoresis along with plasmid (P) DNA control (F).

of dnaA gene, AT-rich sequences and DnaA boxes) and by reference to published studies [11]. oriC regions were amplified by PCR and used to replace the M. hyopneumoniae strain 232 oriC region of pMHO-2, to produce the plasmids pMhyor, pMpulm, pMconj and pMovip. Plasmids containing shortened regions of the $M$. hyopneumoniae strain 232 oriC were constructed as shown in Figure 2. Shortened oriC regions were amplified by PCR from M. hyopneumoniae strain 232 genomic DNA and used to replace the oriC region of pMHO-2 to generate plasmids pOriC-ii, pOriC-iii, pOriC-iv, pOriC$\mathrm{iii} / \mathrm{iv}$ and $\mathrm{pOriC}-\mathrm{iv} / \mathrm{v}$. Some of our M. hyopneumoniae field isolates are more resistant to tetracycline than others. Therefore, as an alternative selection marker to tet $M$ we chose the puromycin $\mathrm{N}$-acetyltransferase (pac) gene conferring resistance to puromycin. pMHO-puro was constructed by inserting the pac gene from pMiniTn4001PsPuro [GenBank: FJ872396] [20] into the PstI cut site of plasmid pMHO. This pac gene also contains the spiralin gene promoter of S. citri.

\section{Southern hybridisation}

Total DNA was extracted from $20 \mathrm{~mL}$ mycoplasma broth culture using a Qiagen DNA Blood \& Tissue kit (Qiagen Ltd, Manchester, UK) and $1 \mu \mathrm{g}$ was digested to completion with HindIII. DNA was separated by electrophoresis on $0.8 \%$ agarose and blotted onto Hybond- $\mathrm{N}+$ membrane (GE Healthcare Ltd, Little Chalfont, UK) using standard methods [21]. DNA was fixed to the membrane by exposure to UV light. DIG-labelled probes specific for the 

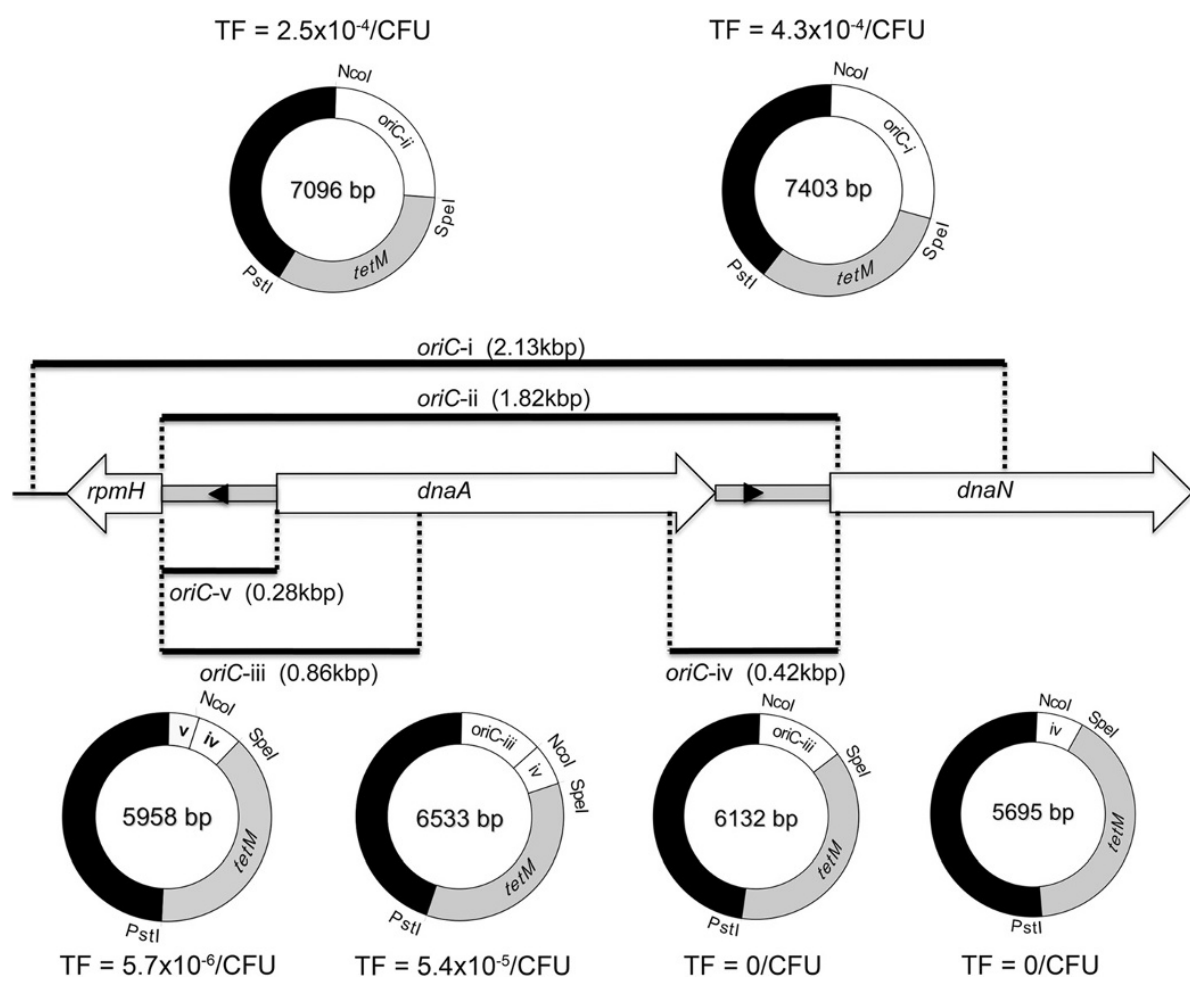

Figure 2 Minimum oriC determination. The predicted oriC region of $M$. hyopneumoniae strain 232 is shown with the location of two putative DnaA boxes (black arrowheads) lying within AT-rich intergenic regions (grey boxes). The oriC region from plasmid pMHO (oriC-i) was reduced in a series of steps to produce five further plasmids (pOric-ii, pOriC-iii, pOriC-iv, pOriC-iii/iv and pOriC-iv/v). M. hyopneumoniae strain 232 was transformed in triplicate with each plasmid and the mean transformation efficiencies (TF) are shown, expressed as the number of transformants per colony forming unit of mycoplasma transformed.

bla ampicillin resistance gene of pGEM-T or the tetM gene were generated from PCR-amplified DNA (see Table 1 for oligonucleotide sequences) using a DIGHigh Prime DNA Labelling and Detection Starter Kit II (Roche Applied Science Ltd, Burgess Hill, UK). The same kit was used to perform pre-hybridisation and hybridisation in accordance with the manufacturers instructions. The membrane was autoradiographed at room temperature using CL-XPosure Film (Fisher Scientific Ltd, Loughborough, UK).

\section{Results}

\section{Generation of $M$. hyopneumoniae transformants}

In our initial attempts at transforming M. hyopneumoniae, we constructed a simple plasmid containing the predicted oriC region of $M$. hyopneumoniae strain 232 and tet $M$ conferring resistance to tetracycline. A large $2.1 \mathrm{kbp}$ region of the $M$. hyopneumoniae strain 232 genome encompassing the entire $d n a A$ gene and upstream and downstream AT-rich regions was selected. Homologous DNA sequences of other mycoplasmas demonstrating a similar gene arrangement have shown success in functioning as an oriC in artificial self-replicating plasmids $[9,11]$. The $t e t M$ gene has been used as a selection marker for mycoplasmas $[10,12]$ and we confirmed the sensitivity of $M$. hyopneumoniae strain 232 to tetracycline. Following the methods of Hannan [22], the minimum inhibitory concentration (MIC) of tetracycline was $0.03 \mu \mathrm{g} / \mathrm{mL}$ in liquid medium and $0.015 \mu \mathrm{g} / \mathrm{mL}$ in solid medium. Following the transformation of $M$. hyopneumoniae strain 232 with $10 \mu \mathrm{g}$ of pMHO-1, cells were incubated for $3 \mathrm{~h}$ at $37^{\circ} \mathrm{C}$ and then plated onto Friis agar containing $2 \mu \mathrm{g} / \mathrm{mL}$ tetracycline. Triplicate repeats were performed and after 14 days incubation, no growth was observed for pMHO-1 or "no DNA" controls. We considered that the tetM promoter sequence may be inactive in $M$. hyopneumoniae and/or that the tetracycline concentration may be too high to be overcome by transformed organisms. The tet $M$ sequence under control of its own promoter, as derived from Enterococcus faecalis, is expressed at levels sufficient to confer tetracycline resistance in several mycoplasmas [12,23-25]. However, other mycoplasmas may require an alternative promoter sequence, such as the spiralin gene promoter of Spiroplasma citri that has be shown to be active in several mycoplasma species $[11,13,14]$. In addition to constructing $\mathrm{pMHO}-2$ utilising tet $M$ and the spiralin gene promoter sequence, we produced plasmids pMHO-3 and $\mathrm{pMHO}-4$ containing tet $M$ with the putative 
promoter regions of the M. hyopneumoniae strain 232 P97 ciliary adhesin gene [26] and lactate dehydrogenase (ldh) gene respectively. In addition to altering the promoter sequences controlling tetM expression, we sought to determine whether or not a lower concentration of tetracycline would enhance the growth of transformants. For other mycoplasmas, transformed cells are typically selected using concentrations of between 2 and $4 \mu \mathrm{g} / \mathrm{mL}$ tetracycline [12,23,25]. Having determined that a concentration of $0.015 \mu \mathrm{g} / \mathrm{mL}$ could inhibit growth of $M$. hyopneumoniae 232 on Friis agar, we lowered the concentration of tetracycline to $0.2 \mu \mathrm{g} / \mathrm{mL}$. M. hyopneumoniae strain 232 was transformed in triplicate with plasmids pMHO-1, pMHO-2, pMHO-3 and pMHO-4 and plated onto Friis agar containing $0.2 \mu \mathrm{g} / \mathrm{mL}$ tetracycline. After incubation for 14 days tetracycline resistant colonies were present in bacteria transformed with all four oriC plasmids but were completely absent in the "no DNA" control, demonstrating activity of the four promoter sequences. Morphologically, colonies were identical to untransformed M. hyopneumoniae colonies, but colony growth lagged by approximately 3 days (Figure 1E). The highest number of transformants was generated using pMHO-2 $\left(2.5 \times 10^{-4} / \mathrm{CFU}\right)$, with fewer for pMHO-3 $\left(5.8 \times 10^{-5} / \mathrm{CFU}\right)$ and pMHO-1 $\left(1.7 \times 10^{-5} / \mathrm{CFU}\right)$, and least with $\mathrm{pMHO}-4\left(8.3 \times 10^{-6} / \mathrm{CFU}\right)$. Individual colonies were picked from agar and grown in Friis medium containing $0.5 \mu \mathrm{g} / \mathrm{mL}$ tetracycline, after which they were sub-cultured every $2-3$ days in $1 \mu \mathrm{g} / \mathrm{mL}$ tetracycline. After three serial passages, plasmid DNA was extracted and separated by electrophoresis. Plasmid DNA was readily identified for each transformant whereas no plasmid DNA was seen with untransformed $M$. hyopneumoniae 232 (Figure 1F). However, less plasmid DNA was detected for $\mathrm{pMHO}-3$ and $\mathrm{pMHO}-4$ transformants. Given that both of these plasmids contain promoter sequences 400$600 \mathrm{bp}$ in size that are identical to M. hyopneumoniae genomic DNA, we suspect that plasmid integration had occurred by homologous recombination.

\section{Optimisation of transformation conditions}

Initially, we selected electroporation conditions of $2.5 \mathrm{kV}$, $100 \Omega$ and $25 \mu \mathrm{F}$ and used a cuvette with a $2 \mathrm{~mm}$ gap as described by Hedreyda et al. [7]. We varied the electroporation voltage from a maximum possible of $2.5 \mathrm{kV}$ down to $0 \mathrm{kV}$ in $500 \mathrm{~V}$ increments and used pMHO-2 to transform M. hyopneumoniae 232. Electroporation voltage was found to have a profound effect on transformation frequency; decreasing voltage to $2 \mathrm{kV}$ resulted in a 10-fold drop in transformation frequency from $5.4 \times 10^{-6} \mathrm{CFU} / \mathrm{mL}$ to $4.2 \times 10^{-7} \mathrm{CFU} / \mathrm{mL}$, and below 2 $\mathrm{kV}$ no transformants were obtained (Table 2). Similarly, decreasing plasmid DNA was associated with a drop in transformation frequency; a drop from $10 \mu \mathrm{g}$ down to
Table 2 Effect of electroporation voltage on transformation frequency.

\begin{tabular}{ll}
\hline Electroporation voltage & $\begin{array}{l}\text { Average transformation frequency } \\
\text { (transformants/CFU) [SE] }\end{array}$ \\
\hline $2.5 \mathrm{kV}$ & $5.4 \times 10^{-6}\left[1.2 \times 10^{-6}\right]$ \\
$2.0 \mathrm{kV}$ & $4.2 \times 10^{-7}\left[3.9 \times 10^{-7}\right]$ \\
$1.5 \mathrm{kV}$ & 0 \\
$1.0 \mathrm{kV}$ & 0 \\
$0 \mathrm{kV}$ & 0
\end{tabular}

The effect of altering the electroporation voltage on transformation frequency was examined. M. hyopneumoniae strain 232 was transformed with pMHO-2 and the average transformation frequencies (with standard error) of three separate transformations are shown.

$1 \mu \mathrm{g}$ resulted in a 10-fold drop in transformants from $5.6 \times 10^{-3} \mathrm{CFU} / \mathrm{mL}$ to $2.5 \times 10^{-4} \mathrm{CFU} / \mathrm{mL}$ (Table 3 ). Attempts to improve transformation frequency further by increasing the DNA concentration above $10 \mu \mathrm{g}$ typically resulted in arcing.

\section{Host species specificity of oriC regions}

Suspecting that the large $2.1 \mathrm{kbp}$ oriC in our plasmids would favour integration by homologous recombination, we determined whether the predicted oriC regions of four phylogenetically closely related Mycoplasma species would function in M. hyopneumoniae. We hypothesised that the oriC regions of one or more of these mycoplasmas may be sufficiently similar to that of $M$. hyopneumoniae to be recognised as an oriC, yet different enough that the incidence of homologous recombination would be reduced. The genomes of $M$. hyorhinis [16], M. pulmonis [17], M. conjunctivae [18] and M. ovipneumoniae [19] exhibited a similar arrangement of genes in the oriC region to $M$. hyopneumoniae, with AT-rich regions and DnaA boxes in the intergenic regions flanking $d n a A$. M. hyopneumoniae strain 232 cells were electroporated in triplicate with plasmids pMHO-2, pMhyor, pMpulm, pMconj and pMovip in two independent experiments and cultured on Friis agar containing $0.2 \mu \mathrm{g} / \mathrm{mL}$ tetracycline.

\section{Table 3 Effect of plasmid DNA concentration on} transformation frequency.

\begin{tabular}{ll}
\hline DNA quantity & $\begin{array}{l}\text { Average transformation frequency } \\
\text { (transformants/CFU) [SE] }\end{array}$ \\
\hline $10 \mu \mathrm{g}$ & $5.6 \times 10^{-3}\left[1.1 \times 10^{-3}\right]$ \\
$5 \mu \mathrm{g}$ & $5.0 \times 10^{-3}\left[1.4 \times 10^{-3}\right]$ \\
$2 \mu \mathrm{g}$ & $3.3 \times 10^{-4}\left[9.6 \times 10^{-5}\right]$ \\
$1 \mu \mathrm{g}$ & $2.5 \times 10^{-4}\left[3.7 \times 10^{-5}\right]$ \\
$0 \mu \mathrm{g}$ & 0 \\
\hline
\end{tabular}

The effect of plasmid DNA concentration of transformation frequency was examined by transforming $M$. hyopneumoniae strain 232 with different quantities of pMHO-2 DNA. Average transformation frequencies (with standard error) of three transformations are shown. 
As expected, many individual tetracycline resistant colonies were obtained with the $\mathrm{pMHO}-2$ plasmid within 10 days but not for "no DNA" controls. However, after 14 days, no colonies were visible in any culture transformed with plasmids containing the oriC regions of the other $\mathrm{Myco-}$ plasma species.

\section{Determination of the minimum functional oriC of M. hyopneumoniae}

As an alternative strategy to reduce the incidence of homologous recombination, we attempted to reduce the size of oriC used in our plasmids. To define the minimum functional oriC in $M$. hyopneumoniae, initially the oriC of pMHO-2 (oriC-i) was reduced by 300 bp by removing excess DNA sequence lying upstream and downstream of the AT-rich intergenic regions (pOriC-ii). With both AT-rich regions and the $\operatorname{dnaA}$ gene still present, as expected, there was no reduction in transformation efficiency (Figure 2). Next, we determined whether each of the two AT-rich intergenic regions flanking the $d n a A$ gene would function as an oriC independently. Plasmids pOriC-iii and pOriC-iv were constructed containing the upstream and downstream intergenic regions respectively. pOriC-iii contained the AT-rich region upstream of $d n a A$, and also extended downstream into $d n a A$ to include three further putative DnaA boxes. M. hyopneumoniae strain 232 was transformed in triplicate with each plasmid but failed to produce any transformants. Therefore, each AT-rich region was unable to function independently as an oriC. However, by placing both intergenic regions adjacent to each other in plasmid pOriC-iii/iv, transformants were produced in all three triplicate transformations. The transformation efficiency was approximately 10-fold lower than when the entire $d n a A$ gene was present (Figure 2). Finally, we constructed plasmid pOriC-iv/v to determine whether or not the entire $d n a A$ gene sequence could be removed leaving the AT-rich intergenic regions alone. Following electroporation of $M$. hyopneumoniae strain 232 with pOriC-iv/v, tetracycline resistant colonies were generated but with a transformation efficiency approximately 100 -fold lower than that achieved when the dnaA gene sequence was included (Figure 2). We concluded that the minimum oriC necessary for functionality in self-replicating plasmids was approximately $700 \mathrm{bp}$ long and included both AT-rich intergenic regions lying upstream and downstream of the $\operatorname{dnaA}$ gene, but that the $d n a A$ gene sequence itself was not essential to this. To determine how robust the resistance to tetracycline of pOriC-iv/v transformants was, we determined the MIC of three individual colonies in triplicate. After initial growth in $1 \mu \mathrm{g} / \mathrm{mL}$, the MIC for tetracycline of all three clones in Friis broth was $32 \mu \mathrm{g} / \mathrm{mL}$ compared to $0.03 \mu \mathrm{g} / \mathrm{mL}$ for untransformed M. hyopneumoniae strain 232 .

\section{Stability of plasmid DNA}

To determine the stability of our plasmids upon serial passage over time, individual transformants were picked into Friis medium containing $0.5 \mu \mathrm{g} / \mathrm{mL}$ tetracycline and passaged 19 times. At passages 3, 8 and 19, total DNA was extracted and Southern hybridisation performed with a DIG-labelled probed specific for the bla ampicillin resistance gene of pGEM-T. For each plasmid, we could readily detect extrachromosomal DNA at every passage, but not for the untransformed $M$. hyopneumoniae strain 232 control (Figure 3A). Additionally, we did not observe a reduction in plasmid DNA quantity that may be suggestive of plasmid integration into the M. hyopneumoniae genome by homologous recombination. We further determined the stability of the minimal oriC plasmid, pOriC-iv/v, over serial passages without selection. Three individual transformants were passaged five times in Friis medium with $0.5 \mu \mathrm{g} / \mathrm{mL}$ tetracycline followed by six passages without tetracycline. At each of the six passages without selection, cultures were plated (in triplicate) onto Friis agar with and without $0.2 \mu \mathrm{g} / \mathrm{mL}$ tetracycline. After 14 days growth, colony counts were performed. We observed a rapid reduction in tetracycline resistant colonies following serial passage in medium containing no tetracycline, showing that selection is necessary to maintain resistance, and suggesting that the transformants can readily be "cured" of plasmid DNA (Figure 3B). We anticipate that this stable plasmid may be useful in generating targeted gene disruptions of $M$. hyopneumoniae. We therefore examined three clones of pMHO-2 (containing oriC-i) transformed M. hyopneumoniae at passage 19 . We predicted that integration of plasmid pMHO-2 into the M. hyopneumoniae strain 232 genome would generate a $4.6 \mathrm{kbp}$ HindIII digestion fragment that would be detected by a DIGlabelled probe annealing to the tet $M$ gene. By separating a larger amount $(2.5 \mu \mathrm{g})$ of HindIII-digested total DNA and using a DIG-labelled tetM gene probe, we were able to visualise a $7.4 \mathrm{kbp}$ band consistent with plasmid DNA in three transformants and a $4.6 \mathrm{kbp}$ band consistent with integrated plasmid DNA in two transformants. This would suggest that recombinase systems active in $M$. hyopneumoniae are capable of allowing homologous recombination to occur, and therefore the minimum oriC plasmid may be useful in directing homologous recombination to target genes. Finally, we found that many of our UK field isolates exhibited greater resistance to tetracycline than M. hyopneumoniae 232, making it unachievable to select for transformed colonies on Friis agar containing $0.2 \mu \mathrm{g} / \mathrm{mL}$ tetracycline (data not shown). To circumvent this problem, we replaced the tet $M$ gene of pMHO-2 with the puromycin N-acetyltransferase (pac) gene from pMiniTn4001PsPuro [20] to generate plasmid pMHOpuro. This pac gene also contains the spiralin gene promoter of $S$. citri and confers resistance to puromycin, 

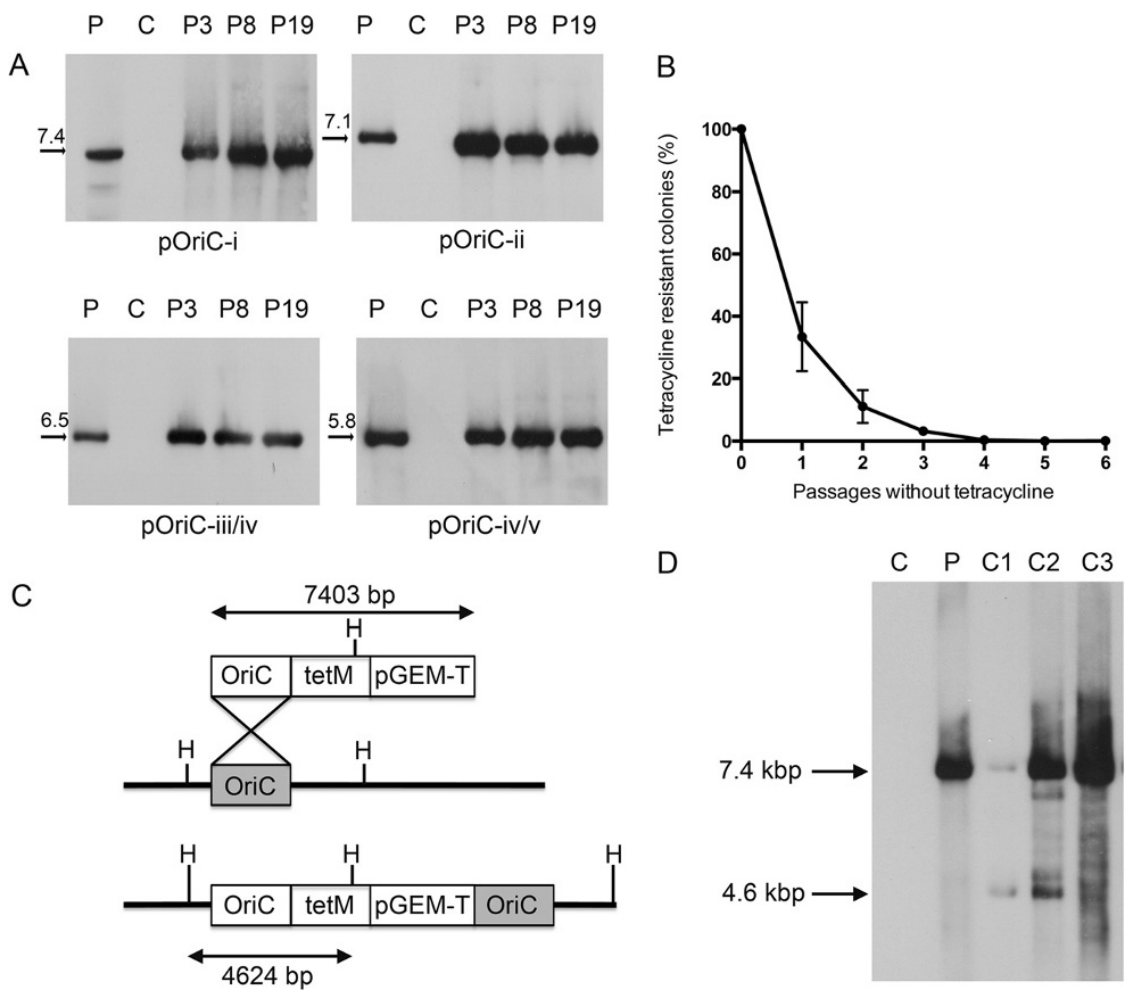

Figure 3 oriC plasmid stability. Individual transformants generated with four plasmids containing various oriC regions were passaged up to 19 times in Friis medium containing tetracycline (A). Genomic DNA was extracted from cultures and analysed by Southern hybridisation using a probe annealing to the bla ampicillin resistance gene. For each plasmid, there was no decline in extrachromosomal DNA over time, and plasmid DNA could still be readily detected after 19 passages. For plasmid pOriC-iv/v, three transformants were passaged up to six times without tetracycline before undergoing selection with tetracycline (B). With each passage without selection, the number of tetracycline-resistant colonies reduced, demonstrating a loss of tetracycline-resistance. Possible integration events were predicted for plasmid pMHO-2 containing oriC-i (C). Three further pMHO-2 transformants were passaged 19 times and total DNA extracts subjected to Southern hybridisation with a tetM DIG-labelled probe, along with plasmid DNA control (P) and untransformed M. hyopneumoniae strain 232 DNA (C) (D). Two clones showed the presence of $7.4 \mathrm{kbp}$ plasmid DNA and also a $4.6 \mathrm{kbp}$ fragment consistent with plasmid integration by homologous recombination.

an aminonucleoside that has no veterinary clinical use, and therefore will be generally applicable as a genetic marker for M. hyopneumoniae. Transformation of M. hyopneumoniae strain 232 with pMHOpuro resulted in a transformation frequency of $1.6 \times 10^{-4} / \mathrm{CFU}$ compared to $4.6 \times 10^{-5}$ for plasmid pMHO-2 (containing the tet $M$ gene). Thus puromycin may be a suitable selection marker for M. hyopneumoniae isolates that are resistant to tetracycline.

\section{Discussion}

The inability to genetically manipulate $M$. hyopneumoniae has been a major obstacle to progress in understanding the survival and pathogenesis of the organism. Using simple artificial self-replicating plasmids containing the oriC of $M$. hyopneumoniae and an antimicrobial resistance gene, we have shown for the first time that the organism is susceptible to transformation. We found that the transformation conditions optimised by Hedreyda et al. [7] and used widely in other Mycoplasmas are suitable for M. hyopneumoniae. However, other critical factors include titration of the tetracycline concentration to a level that can readily be overcome by the TetM resistance protein, the use of high voltage for electroporation and the use of a large excess of plasmid DNA. Additionally, we found that the choice of promoter affected the expression of the tetM gene, and as is the case with other mycoplasmas, the spiralin gene promoter of Spiroplasma citri is a suitable choice for $M$. hyopneumoniae. Our oriC system allowed us to assess the function of putative M. hyopneumoniae promoter sequences, and confirmed the identity of two promoter sequences that were active in controlling tet $M$ expression. The $P 97$ promoter sequence was recently predicted and we have verified that this is functional in our plasmid system [26]. Using the criteria identified by Weber Sde et al. [26], we also predicted the location of the $l d h$ promoter, and again demonstrated its activity in our plasmid system. These M. hyopneumoniaespecific promoters will be valuable in the generation of further tools for the genetic manipulation of the organism. Using our system, we verified that the origin of replication 
of $M$. hyopneumoniae lies in the region of $d n a A$ and includes two short AT-rich regions. It has been suspected that the oriC of $M$. hyopneumoniae lies in this region, but unusually within the AT-rich regions there are only two DnaA boxes that resemble the E. coli consensus sequence, whereas for other mycoplasma species, there are typically multiple DnaA boxes [2]. Additional DnaA boxes are present within the $d_{n a A}$ gene, but these are not required for a functional oriC. We hypothesised that the oriC regions of mycoplasmas showing a high degree of nucleotide sequence similarity to $M$. hyopneumoniae would function in M. hyopneumoniae, and enable stable plasmid maintenance without integration by homologous recombination. However, it appears that oriCs are very specific to their host species and none of the oriC regions from four closely related Mycoplasma species functioned in M. hyopneumoniae.

The minimum $M$. hyopneumoniae sequence that functioned in an oriC plasmid (pOriC-iv/v) was approximately $700 \mathrm{bp}$ in length and included both AT-rich regions. This plasmid was maintained extrachromosomally over at least 19 passages with selection pressure, equivalent to over 8 weeks post-transformation. However, when selection pressure was removed, tetracycline resistance was rapidly lost within 5 passages. Having demonstrated that plasmids carrying sequences with a high degree of homology to regions of the $M$. hyopneumoniae genome can undergo integration by homologous recombination, it is likely that this plasmid will be useful in generating targeted disruptions in genes of interest. By incorporating sequences encoding mycoplasma genes of interest, it is likely that we will be able to direct homologous recombination and cause disruption of these genes, as has been shown with other mycoplasmas $[11,12]$. In addition to tet $M$, we demonstrated that pac conferring resistance to puromycin can be expressed in M. hyopneumoniae strain 232 from our oriC plasmids when driven by the spiralin gene promoter sequence of $S$. citri. While $M$. hyopneumoniae strain 232 is exquisitely sensitive to tetracycline, as demonstrated in this study, many of our recent field isolates of $M$. hyopneumoniae are relatively resistant (data not shown). However, these strains are susceptible to puromycin, therefore pac may be a more suitable selection marker for generating transformants in other M. hyopneumoniae isolates.

In summary, we have shown that M. hyopneumoniae is indeed susceptible to genetic manipulation by transformation with self-replicating plasmids. In doing so, we have developed a system that will undoubtedly be useful in genetic studies of $M$. hyopneumoniae and probably other mycoplasma species. Additionally, we anticipate that our findings will be a key step towards the development of a transposon-mediated system to generate random mutants of $M$. hyopneumoniae, which will take us a step closer to unraveling the pathogenesis of this poorly understood pathogen.

\section{Additional file}

Additional file 1: BRaDP1T consortium. List of researchers

collaborating in the BRaDP1T consortium.

\section{Competing interests}

The authors declare that they have no competing interests.

\section{Author's contributions}

Experiments were conceived by GAM, ANR \& BSC. Experiments were performed by GAM, ASD \& DM. BSC, JTB, ANR, PL, BWW, AWT and DJM assisted with experimental design. The manuscript was written by GAM \& ANR and was approved by all authors.

\section{Acknowledgements}

This work was supported by a Longer and Larger (LoLa) grant from the Biotechnology and Biological Sciences Research Council (grant numbers BB/ G020744/1, BB/G019177/1, BB/G019274/1 and BB/G018553/1), the UK Department for Environment, Food and Rural Affairs and Zoetis awarded to the Bacterial Respiratory Diseases of Pigs-1 Technology (BRaDP1T) consortium (see Additional file 1). The funders had no role in study design, data collection and analysis, decision to publish, or preparation of the manuscript. We thank Joel Renaudin for the gift of the PSRT2 plasmid and Jaume Pinyol for the pIVT plasmid.

\section{Author details}

${ }^{1}$ Department of Pathology and Pathogen Biology, The Royal Veterinary College, Hawkshead Lane, North Mymms, Hatfield AL9 7TA, United Kingdom. ${ }^{2}$ Section of Paediatrics, Imperial College London, St Mary's Campus, London W2 1PG, United Kingdom. ${ }^{3}$ Department of Veterinary Medicine, University of Cambridge, Madingley Road, Cambridge CB3 OES, United Kingdom.

${ }^{4}$ Department of Pathogen Molecular Biology, London School of Hygiene \& Tropical Medicine, Keppel Street, London WC1E 7HT, United Kingdom.

Received: 23 April 2013 Accepted: 10 July 2013

Published: 29 July 2013

\section{References}

1. Maes D, Segales J, Meyns T, Sibila M, Pieters M, Haesebrouck F: Control of Mycoplasma hyopneumoniae infections in pigs. Vet Microbio/ 2008, 126:297-309.

2. Minion FC, Lefkowitz EJ, Madsen ML, Cleary BJ, Swartzell SM, Mahairas GG: The genome sequence of Mycoplasma hyopneumoniae strain 232, the agent of swine mycoplasmosis. J Bacteriol 2004, 186:7123-7133.

3. Pour-El I, Adams C, Minion FC: Construction of mini-Tn4001tet and its use in Mycoplasma gallisepticum. Plasmid 2002, 47:129-137.

4. Cao J, Kapke PA, Minion FC: Transformation of Mycoplasma gallisepticum with Tn916, Tn4001, and integrative plasmid vectors. J Bacteriol 1994, 176:4459-4462.

5. Dybvig K, French CT, Voelker LL: Construction and use of derivatives of transposon Tn4001 that function in Mycoplasma pulmonis and Mycoplasma arthritidis. J Bacteriol 2000, 182:4343-4347.

6. Hahn TW, Mothershed EA, Waldo RH 3rd, Krause DC: Construction and analysis of a modified Tn4001 conferring chloramphenicol resistance in Mycoplasma pneumoniae. Plasmid 1999, 41:120-124.

7. Hedreyda CT, Lee KK, Krause DC: Transformation of Mycoplasma pneumoniae with Tn4001 by electroporation. Plasmid 1993, 30:170-175.

8. Reddy SP, Rasmussen WG, Baseman JB: Isolation and characterization of transposon Tn4001-generated, cytadherence-deficient transformants of Mycoplasma pneumoniae and Mycoplasma genitalium. FEMS Immunol Med Microbiol 1996, 15:199-211.

9. Chopra-Dewasthaly R, Zimmermann M, Rosengarten R, Citti C: First steps towards the genetic manipulation of Mycoplasma agalactiae and Mycoplasma bovis using the transposon Tn4001mod. Int J Med Microbiol 2005, 294:447-453. 
10. Chopra-Dewasthaly R, Marenda M, Rosengarten R, Jechlinger W, Citti C: Construction of the first shuttle vectors for gene cloning and homologous recombination in Mycoplasma agalactiae. FEMS Microbiol Lett 2005, 253:89-94

11. Cordova CM, Lartigue C, Sirand-Pugnet P, Renaudin J, Cunha RA, Blanchard A: Identification of the origin of replication of the Mycoplasma pulmonis chromosome and its use in oriC replicative plasmids. J Bacterio/ 2002, 184:5426-5435.

12. Lee SW, Browning GF, Markham PF: Development of a replicable oriC plasmid for Mycoplasma gallisepticum and Mycoplasma imitans, and gene disruption through homologous recombination in M. gallisepticum. Microbiology 2008, 154:2571-2580.

13. Janis C, Lartigue C, Frey J, Wroblewski H, Thiaucourt F, Blanchard A, Sirand-Pugnet $\mathrm{P}$ : Versatile use of oriC plasmids for functional genomics of Mycoplasma capricolum subsp. capricolum. Appl Environ Microbiol 2005, 71:2888-2893.

14. Lartigue C, Blanchard A, Renaudin J, Thiaucourt F, Sirand-Pugnet P: Host specificity of mollicutes oriC plasmids: functional analysis of replication origin. Nucleic Acids Res 2003, 31:6610-6618.

15. Kobisch M, Friis NF: Swine mycoplasmoses. Rev Sci Tech 1996, 15:1569-1605.

16. Calcutt MJ, Foecking MF, Rosales RS, Ellis RJ, Nicholas RA: Genome sequence of Mycoplasma hyorhinis strain GDL-1. J Bacteriol 1848, 2012:194.

17. Chambaud I, Heilig R, Ferris S, Barbe V, Samson D, Galisson F, Moszer I, Dybvig K, Wroblewski H, Viari A, Rocha EP, Blanchard A: The complete genome sequence of the murine respiratory pathogen Mycoplasma pulmonis. Nucleic Acids Res 2001, 29:2145-2153.

18. Calderon-Copete SP, Wigger G, Wunderlin C, Schmidheini T, Frey J, Quail MA, Falquet $\mathrm{L}$ : The Mycoplasma conjunctivae genome sequencing, annotation and analysis. BMC Bioinformatics 2009, 10(Suppl 6):S7.

19. Yang F, Tang C, Wang Y, Zhang H, Yue H: Genome sequence of Mycoplasma ovipneumoniae strain SC01. J Bacteriol 2011, 193:5018.

20. Algire MA, Lartigue C, Thomas DW, Assad-Garcia N, Glass Jl, Merryman C: New selectable marker for manipulating the simple genomes of Mycoplasma species. Antimicrob Agents Chemother 2009, 53:4429-4432.

21. Sambrook JJ, Russell DDW: Molecular Cloning: A Laboratory Manual. $3^{\text {rd }}$ edition. New York: Cold Spring Harbor Laboratory Press; 2001.

22. Hannan PC: Guidelines and recommendations for antimicrobial minimum inhibitory concentration (MIC) testing against veterinary mycoplasma species. International Research Programme on Comparative Mycoplasmology. Vet Res 2000, 31:373-395.

23. Whetzel PL, Hnatow LL, Keeler CL Jr, Dohms JE: Transposon mutagenesis of Mycoplasma gallisepticum. Plasmid 2003, 49:34-43.

24. Glass Jl, Assad-Garcia N, Alperovich N, Yooseph S, Lewis MR, Maruf M, Hutchison CA 3rd, Smith HO, Venter JC: Essential genes of a minimal bacterium. Proc Natl Acad Sci U S A 2006, 103:425-430.

25. French $C T$, Lao P, Loraine AE, Matthews BT, Yu H, Dybvig K: Large-scale transposon mutagenesis of Mycoplasma pulmonis. Mol Microbiol 2008 69:67-76.

26. Weber Sde S, Sant'Anna FH, Schrank IS: Unveiling Mycoplasma hyopneumoniae promoters: sequence definition and genomic distribution. DNA Res 2012, 19:103-115.

\section{doi:10.1186/1297-9716-44-63}

Cite this article as: Maglennon et al: Development of a self-replicating plasmid system for Mycoplasma hyopneumoniae. Veterinary Research 2013 44:63.

\section{Submit your next manuscript to BioMed Central and take full advantage of:}

- Convenient online submission

- Thorough peer review

- No space constraints or color figure charges

- Immediate publication on acceptance

- Inclusion in PubMed, CAS, Scopus and Google Scholar

- Research which is freely available for redistribution 